\title{
As metafunções textual, ideacional e interpessoal em textos multimodais de livros didáticos de espanhol
}

\author{
Larisse Lázaro Santos Pinheiro \\ PPGLA - Universidade de Brasília \\ larisselazaro@hotmail.com \\ Janaína de Aquino Ferraz \\ Universidade de Brasília \\ ferraz.jana@gmail.com
}

\section{Resumo}

Este artigo analisa como os textos multimodais e as metafunções estão inseridas no LD de espanhol. A pesquisa é centrada nos pressupostos teóricos da Linguística Sistêmico-Funcional de Halliday (1978), base teórica dos estudos da Teoria da Semiótica Social/Multimodalidade (KRESS; van LEEUWEN, 2006) e Análise de Clusters (BALDRY; THIBAULT, 2006), que definem o texto multimodal como aquele que tem seus significados realizados por várias semioses. $\mathrm{O}$ artigo configura-se como uma pesquisa de natureza qualitativa em que se privilegia a (re)interpretação de dados. As análises permitem reflexão sobre a composição dos textos multimodais no $\mathrm{LD}$, demonstrando as peculiaridades inerentes à sua composição e como a língua é entendida como parte do contexto sociocultural.

Palavras-chave: Textos multimodais. Metafunções. Livro didático.

\begin{abstract}
This paper analyzes how the multimodal texts and metafunctions are inserted in the LD Spanish. The research is focused on the theoretical Systemic Functional Linguistics Halliday (1978), the basis of studies of the Theory of Social Semiotics / Multimodality (KRESS; van LEEUWEN, 2006) and Cluster Analysis (BALDRY; THIBAULT, 2006), define the multimodal text as one that has its meanings carried by several semiosis. The article is configured as a qualitative research that focuses on the (re) interpretation of data. The analyzes allow reflection on the composition of multimodal texts in LD, showing the peculiarities inherent to its composition, and how language is understood as part of sociocultural context.
\end{abstract}

Keywords: Multimodal texts. Metafunctions. Textbook. 
As metafunções textual, ideacional e interpessoal em textos multimodais...

\section{Introdução}

A língua espanhola está em evidência e é importante meio de comunicação no mundo globalizado, aprendê-la tornou-se necessidade, e seu ensino tem sido muito debatido e está avançando principalmente em relação aos livros didáticos (doravante LD) como componente curricular obrigatório.

A principal finalidade desta pesquisa é investigar como os textos multimodais estão inseridos no LD de espanhol como língua estrangeira (doravante ELE). $\mathrm{O}$ LD no ensino de línguas é fundamental ao planejamento de cursos e currículos escolares, sendo muitas vezes a única fonte para os professores conduzirem suas aulas. É necessário que esses livros ofereçam condições de aprendizado com atividades que proporcionem a construção de sentido e a familiarização com textos diversos (DELL'ISOLA, 2009).

Diante dessa perspectiva, o estudo proposto busca analisar um LD atualmente adotado no ensino regular do espanhol no Brasil, tendo como foco o texto multimodal inserido nesse livro, e como as metafunções estão presentes nesse texto, observando a constituição multimodal e, assim, discutir como a linguagem nos textos multimodais deve ser analisada na perspectiva da sociedade e da cultura à qual pertence, visto que a dimensão social é ponto de partida para a análise dos signos.

Segundo a Teoria da Semiótica Social/Teoria da Multimodalidade, base teórica deste trabalho, o significado surge nas situações e nas interações sociais. O social é a origem e o criador do significado (KRESS; van LEEUWEN, 2006). Por isso é necessário, no LD, internalizar novos hábitos linguísticos e inserir textos que combinem cores, imagens e layouts criativos, ou seja, textos multimodais, que, segundo Kress e van Leeuwen (2006), são aqueles que utilizam mais de um recurso semiótico na sua construção textual (usam recurso verbal e não verbal). Por conseguinte, a combinação dos recursos semióticos comum em textos pode favorecer o processo ensino/aprendizagem de línguas.

Um texto multimodal possibilita várias análises, e dentre essas destacamos a Análise de Clusters (BALDRY; THIBAULT, 2006) - que enfatiza a inter-relação entre os aspectos verbais e os não verbais e como os recursos semióticos estão dispostos na página - e a Gramática Visual 
(KRESS; van LEEUWEN, 2006) - que corresponde à organização dos diversos elementos não verbais no texto.

Isso posto, os objetivos desta pesquisa são investigar como o texto multimodal está inserido no LD de espanhol e como as metafunções textual, ideacional e interpessoal estão presentes nesse texto. $\mathrm{O}$ corpus de pesquisa é o LD Ventana al español - volume 2 (AMENDOLA; ADRIANA, 2011), destinado aos alunos do Ensino Fundamental II, da Editora Moderna (Santillana), analisado em perspectiva multimodal.

Diante dos objetivos, observamos que a composição das linguagens verbal e não verbal, que envolvem várias combinações de recursos semióticos, tem importante função comunicativa no LD de espanhol. Assim, contextualizamos na próxima seção os pressupostos teóricos que embasaram a pesquisa: a linguística Sistêmico-Funcional de Michael Halliday (1978) - base teórica dos estudos da Teoria da Semiótica Social/Multimodalidade (KRESS; van LEEUWEN, 2006) - e a Análise de Clusters (BALDRY; THIBAULT, 2006).

\section{Teoria da Multimodalidade}

O trabalho multimodal sistematizado é de grande relevância para o desenvolvimento de atividades que envolvam semioses diferentes da escrita (FERRAZ, 2011). Para Kress e van Leeuwen (2006), a leitura de textos multimodais é socialmente determinada e é impossível interpretá-los prestando atenção apenas aos aspectos verbais, pois todos os outros modos semióticos também devem ser levados em consideração. Conforme Vieira (2007, p. 10), “o enfoque multimodal visa a transpor esse nível de análise e pretende compreender os diferentes modos de representação que entram no texto com a mesma precisão com que se faz a análise do texto linguístico".

Segundo Kress e van Leeuwen (2006), a Semiótica Social é a base teórica dos estudos da Multimodalidade. Ela começou com as pesquisas de Michael Halliday (1978), da Linguística Sistêmico-Funcional, que afirmava que a linguagem não podia ser analisada de maneira isolada, desvinculada da sociedade e da cultura à qual pertence, pois a dimensão social é o ponto de partida para a análise dos signos nessa teoria. Maroun (2007, p. 91) expande o construto ao afirmar que "na Teoria da Semiótica Social, a língua é entendida como parte de um contexto sociocultural, no qual cultura é entendida como produto de um processo de construção social". 
Desse modo, a metodologia de análise e classificação das estruturas visuais está classificada dentro das metafunções de Halliday (1994): a) ideacional; b) interpessoal; c) textual, que significam: a) representação das experiências de mundo por meio da linguagem; b) estratégias de aproximação/afastamento para com o leitor; c) modos de organização do texto.

Baldry e Thibault (2006) ressaltam que o aumento de outros sistemas semióticos - como representação, gesto, sinal, movimento e música - tem características metafuncionais. "Diferentes modalidades de textos multimodais são integradas pela base dos princípios gerais da organização metafuncional"1 (BALDRY; THIBAULT, 2006, p. 23).

Kress e van Leeuwen (2006) afirmam que a Semiótica Social concebe as regras como socialmente produzidas e mutáveis por meio da interação social. Para a Semiótica Social, o significado surge nas situações e nas interações sociais. O social é a origem e o criador do significado. No entanto, essa concepção vai de encontro à definição da vertente tradicional da Semiótica (Saussure), na qual as regras são consideradas fixas e imutáveis.

Segundo a Semiótica Social, o signo não é uma relação arbitrária entre o significante e o significado, pelo contrário, a formação de um signo é motivada. Os locutores escolhem as formas que consideram adequadas para a expressão do significado pretendido, e o que influencia a representação motivada do signo são as práticas sociais e culturais do grupo (KRESS; van LEEUWEN, 2006). Essa nova visão transcende a tradicional Semiótica e concentra-se no social e na textualidade. Ela enfatiza todas as formas de significação da atividade social. O enfoque multimodal pretende compreender os diferentes modos de representação (VIEIRA, 2007).

A Semiótica Social enfatiza também os recursos semióticos, que, segundo Jewitt e Oyama (2007, p. 136), são “produtos de histórias culturais e de recursos cognitivos que usamos para criar significados na produção e na interpretação de mensagens visuais e de outros tipos". ${ }^{2}$ A comunicação visual envolve a descrição de recursos semióticos, o que pode ser dito e

\footnotetext{
1“"There are general metafunctional principles of organisation which provide a basis for the integration of different modalities in multimodal texts."

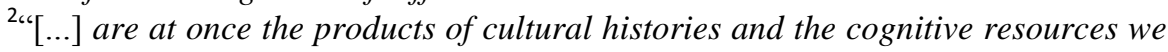
use to create meaning in the production and interpretation of visual and other messages."
}

Horizontes de Linguística Aplicada, ano 16, n. 2, 2017 
feito com imagens (e outros meios de comunicação visual). Em vista disso, com base na Teoria da Semiótica Social, apresentamos a Análise de Clusters, proposta por Baldry e Thibault (2006), pressuposto teórico que sustenta nossa análise.

\subsection{Análise de Clusters}

Um texto multimodal integra diferentes recursos semióticos, como elementos visuais, espaciais e linguísticos, em vários níveis de organização textual, e os diversos tipos de recursos são combinados na construção de significados. Esses textos possibilitam várias análises multimodais, e dentre essas se destaca a Análise de Clusters:

[...] o termo cluster refere-se ao conjunto local de itens, em particular em uma webpage ou página impressa. Os itens em um cluster específico podem ser visuais, verbais, etc. São espacialmente próximos, definindo uma região específica ou uma sub-região da página como um todo ${ }^{3}$ (BALDRY; THIBAULT, 2006, p. 31).

A análise multimodal destaca como aspectos verbais e não verbais são funcionalmente relacionados uns com os outros. Analisar clusters ajuda a visualizar, em abordagem macro, como eles estão contidos dentro de outros maiores e também, de forma mais detalhada, a disposição dos itens multimodais de maior escala e os de menor escala. Essa análise é ferramenta muito importante para a compreensão de como recursos semióticos estão dispostos na página e como estes interagem para produzir significados.

Segundo Baldry e Thibault (2006), a página impressa integra muitos recursos de construção de significado e tem formas típicas de organização que fornecem acesso aos significados potenciais pela especificação de possíveis trajetórias de leitura. Consequentemente, para analisar os percursos gerativos de sentido dos textos multimodais do LD de espanhol

\footnotetext{
3،"The term cluster refers to a local grouping of items, in particular, on a printed or web page. The items in a particular cluster may be visual, verbal and so on and are spatially proximate thereby defining a specific region or subregion of the page as whole."
}

Horizontes de Linguística Aplicada, ano 16, n. 2, 2017 
As metafunções textual, ideacional e interpessoal em textos multimodais...

faz-se necessário verificar a trajetória de leitura por meio dos clusters e como os recursos semióticos se interligam e constroem sentidos.

Para a Análise de Clusters é necessário compreender a lógica organizacional da página impressa. Nesse sentido, alguns questionamentos são importantes para a definição de página impressa:

[...] como é que a página se comunica? Como é que a imagem visual organiza as pessoas, objetos, as ações que executam $e$ as configurações em que estes ocorrem em um conjunto estruturado de relações? Como é que a página dá estrutura para as relações entre o mundo representado do texto e do espectador do texto? E, em termos mais gerais, como se indica ao leitor/espectador as formas possíveis de ler o texto e a prioridade informacional relativa a serem atribuídos aos diferentes componentes da composição visual? Como podemos analisar e teorizar - estes vários aspectos do modo como os textos visuais se comunicam? ${ }^{4}$ (BALDRY; THIBAULT, 2006, p. 57).

Essas indagações são a base para a Análise de Clusters deste artigo tanto em termos de análise de texto e transcrição multimodal como das maneiras em que o quadro metafuncional (HALLIDAY, 1994), citado anteriormente, pode nos ajudar a compreender muitos aspectos da página impressa, como o arranjo espacial dos itens na página, a relação entre textos verbais e não verbais, as relações entre leitor e texto multimodal e assim por diante (BALDRY; THIBAULT, 2006). Portanto, a análise da página impressa possibilita a compreensão de como os vários recursos semióticos contribuem de diferentes maneiras para as várias dimensões do significado de um texto multimodal (BALDRY; THIBAULT, 2006).

Dessa forma, apresentamos na próxima seção o outro pressuposto teórico que embasa este artigo: a Gramática do Design Visual, proposta por

\footnotetext{
${ }^{4 "}$ "How does the page communicate? How does the visual image organise the persons, objects, the actions they perform, and the settings in which these occur into a structured set of relations? How does the page give structure to the relations between the represented world of the text and the viewer of the text? And, more generally speaking, how does it indicate to the reader/viewer the possible ways of reading the text and the relative information priority to be assigned to the different component parts of the overall visual composition? How can we talk about analyse and theorise - these various aspects of the way visual texts communicate?"
} Horizontes de Linguística Aplicada, ano 16, n. 2, 2017 
Kress e van Leeuwen (2006), que corresponde à organização dos diversos elementos não verbais com a finalidade de estabelecer sentidos.

\subsection{Gramática do Design Visual}

Kress e van Leeuwen (2006) elaboraram a Gramática do Design Visual devido à importância e à necessidade de se desenvolver um método de análise que possibilitasse verificar como todos os recursos semióticos presentes em um texto constroem, de maneira conjunta, significados sociais (KRESS; van LEEUWEN, 2006). Conforme os autores supracitados, a Gramática do Design Visual relaciona-se às nossas formas de interação social e cultural, propondo-se a descrever como indivíduos, coisas e lugares são combinados em uma totalidade constitutiva de sentido.

Os recursos semióticos funcionam juntos em um texto na forma como são combinados, pois há harmonia entre as semioses verbal e não verbal. Dionísio e Hoffnagel (2005, p. 159) contribuem ao afirmar que "imagem e palavra mantêm uma relação cada vez mais próxima, cada vez mais, integrada".

Nessa perspectiva, Baldry e Thibault (2006) propõem modos de generalizar o método de Halliday ao combinar palavras com imagens, sons, ações e outros meios. Segundo esses autores, a linguagem é funcional, ou seja, está fazendo algum trabalho em algum contexto, ao contrário de palavras e frases isoladas. Eles fazem paralelo com as metafunções ideacional, interpessoal e textual, que passam a ser denominadas respectivamente de representacionais, interativas e composicionais.

Conforme Kress e van Leeuwen (2006), os mesmos princípios regem não só as imagens, como também os textos multimodais. Assim, como o foco desta pesquisa são os textos multimodais no LD de espanhol, a análise de significados composicionais (valor informativo, saliência e enquadramento) e representacionais (estrutura narrativa e conceitual) será de grande relevância.

Na Gramática do Design Visual, os significados potenciais dos recursos semióticos são mapeados em redes de sistemas, e estas fornecem ferramentas para análise (FERRAZ, 2011). O uso de instrumentos adequados na pesquisa é de suma importância para se trilhar caminho seguro. Por isso escolhemos métodos capazes de nos auxiliar de maneira significativa e concreta, foco da próxima seção. 
As metafunções textual, ideacional e interpessoal em textos multimodais...

\section{Metodologia}

O estudo apresentado neste artigo é uma pesquisa de metodologia qualitativa, que busca revelar como os textos multimodais estão inseridos no LD de ELE. Para tanto, a análise dos dados, de caráter interpretativista, apresenta-se como a mais adequada. Nesse sentido, a pesquisa qualitativa deve expor algumas características, tais como:

[...] escolha adequada de métodos e teorias convenientes; no reconhecimento e na análise de diferentes perspectivas; nas reflexões dos pesquisadores a respeito de suas pesquisas como parte do processo de produção de conhecimento; e na variedade de abordagens e métodos (FLICK, 2009, p. 23).

A vertente qualitativa enfatiza a natureza da realidade socialmente construída, a relação próxima entre o pesquisador, a pesquisa e as restrições que a moldam (MOURA FILHO, 2000). Dessa maneira, a compreensão interpretativa dos textos é de suma importância para o desenvolvimento do estudo aqui relatado. É necessário que o pesquisador esteja consciente de que as interpretações construídas serão sempre baseadas e subsidiadas pelas teorias apresentadas na fundamentação teórica e que suas interpretações são apenas algumas das muitas possibilidades existentes.

O corpus de pesquisa é a coleção Ventana al español - volume 2 (destinada aos alunos dos Ensino Fundamental II) da Editora Moderna (Santillana). Para a seleção desse corpus focamos em LD de ELE, que possui uma concepção de língua estrangeira (LE) como instrumento de comunicação. A visão de língua desse $\mathrm{LD}$ é de uma atividade social e interativa. Ele oferece aos alunos uma diversidade de textos multimodais de diferentes gêneros em situações reais de uso da língua.

A compreensão interpretativa dos textos é de suma importância para o desenvolvimento do estudo. Por meio de análise documental, na coleta de dados observamos os textos multimodais e as metafunções textual, ideacional e interpessoal presentes no LD de ELE. Desse modo, a pesquisa qualitativa permite ampla análise e interpretação dos dados. 


\section{Análise de texto multimodal}

Analisamos a seção de leitura de uma unidade didática do LD. As páginas que compõem a seção apresentam diferentes recursos semióticos em sua composição e são consideradas textos multimodais, uma vez que assumimos a abordagem proposta por Kress e van Leeuween (2006), cuja definição de texto multimodal é aquele que tem seus significados realizados por mais de uma semiose.

$\mathrm{O}$ texto multimodal encontra-se nas páginas 16 e 17 pertencente à Unidade I - Mi día es así... Apresenta o gênero discursivo (BAKHTIN, 1997) "guia de viagem", que não se limita à linguagem verbal, mas que se amplia para a modalidade visual com mapas e fotos complementando o texto verbal, com iguais potencialidades de significação.

\subsection{Análise de Clusters}

O gênero "guia de viagem" tem como objetivo principal orientar o turista e ressaltar as belezas e as possibilidades de passeios oferecidas pelo destino turístico com o intuito de atrair visitantes. Para a análise do texto multimodal, destacamos da página 16 três clusters com potencialidades de significação, conforme podemos observar na figura 1 .

No cluster 1 há um enquadramento enfatizando o título da seção, porém devido à cor clara não se destaca como deveria. O cluster 2 é composto por dois subclusters: o 2a apresenta o gênero guia de viagem, a ser abordado na seção de leitura; no 2 b há enquadramento com texto explicativo sobre o que é um guia de viagem e quais informações estão contidas nesse gênero. Observa-se que a metafunção textual está presente no subcluster $2 \mathrm{~b}$, pois a organização textual é evidenciada, como se observa nas seguintes frases: "La guia de viaje es una selección impresa o electrónica [...]"; "Contíene informaciones sobre transporte [...]". 
Figura 1. Análise de Clusters I
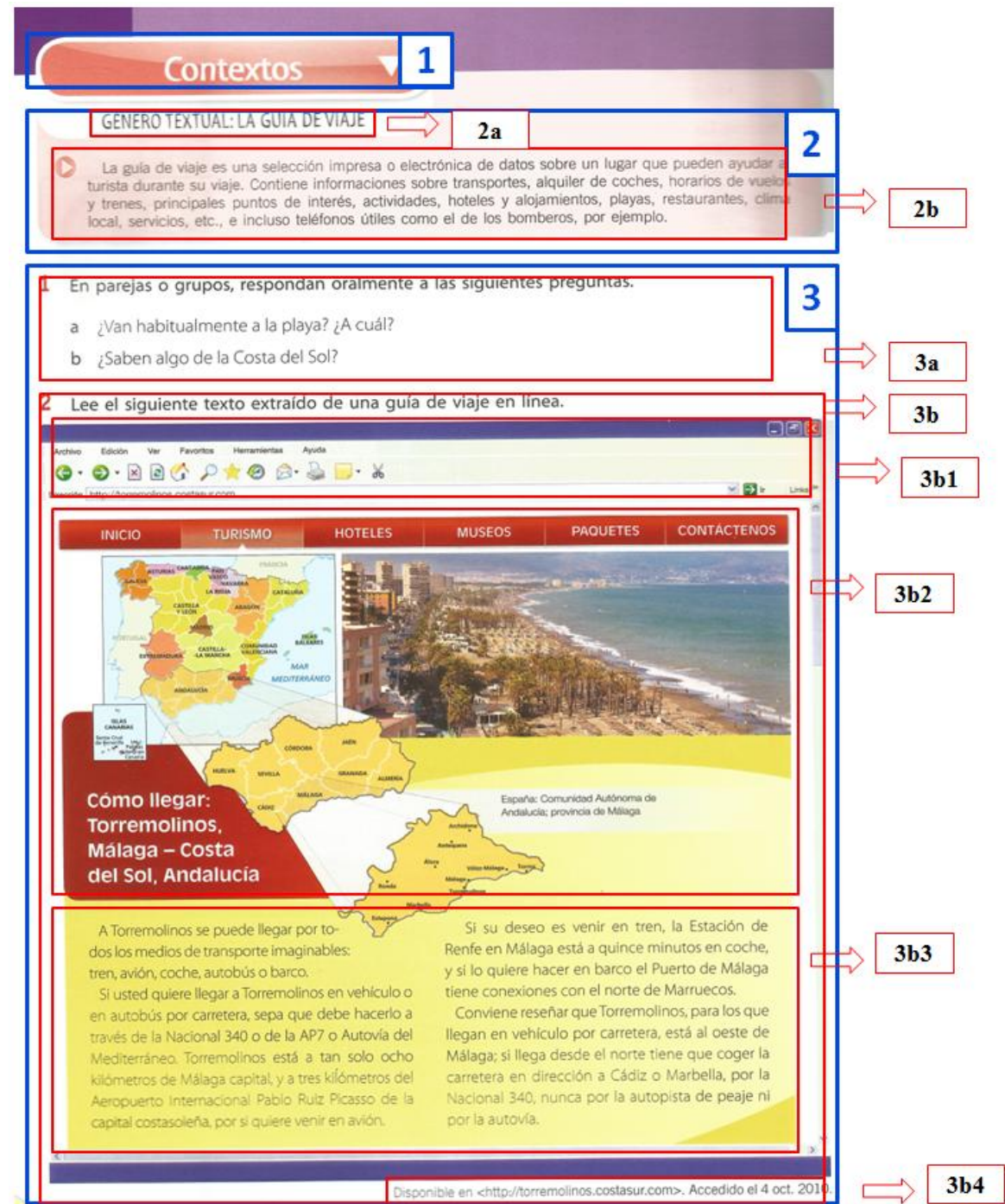

Fonte: ALMEIDA; AMENDOLA (2011, p. 16) 
O cluster 3 é composto por vários subclusters (marcados em vermelho na Figura 1) e indica perguntas sobre o tema para os alunos responderem oralmente e em duplas. A metafunção ideacional é evidenciada por meio de perguntas marcadas no subcluster 3a: “ ¿Van habitualmente a la playa? ¿A cuál?/ ¿Saben algo de la Costa del Sol?”assim os alunos expressam suas percepções de mundo, refletindo a realidade na língua. No subcluster 3b, com vários subclusters, apresenta-se o texto base, um guia de viagem da Costa do Sol - Torremolinos, situada na comunidade autônoma de Andaluzia, província de Málaga.

O guia é colorido e bem ilustrado, está apresentado no suporte no qual é veiculado (site - www.torremolinos.costasur.com). Os ícones visuais, como mapas e fotos, complementam o texto verbal e contribuem significativamente na construção de sentido deste. A função interpessoal é destacada, pois o uso da língua, por meio do gênero discursivo, está presente no texto, que fala diretamente com o leitor, utilizando com frequência o modo imperativo, como em "Date um paseo [...]”, e também a segunda pessoa do singular do presente do indicativo, como em " [...] puedes ir a parques acuáticos [...]”, tempo verbal trabalhado na unidade. Por conseguine, essa função refere-se ao significado do ponto de vista do seu processo de interação social, da língua como ação.

Nessa mesma perspectiva de análise, na página 17 destacamos dois clusters, de acordo com a Figura 2.

O cluster 4 é composto de três subclusters referentes às questões propostas sobre o texto apresentado. O objetivo é introduzir o gênero guia de viagem e falar um pouco sobre os meios de transporte, um dos temas da unidade. No subcluster $4 \mathrm{c}$, a atividade trabalha com a intertextualidade, que se refere ao diálogo entre um texto e outro, que pode manifestar-se de forma explícita, quando há referência ao texto-fonte, ou implícita, quando as informações são recuperadas com base nos conhecimentos prévios do leitor (KOCH; ELIAS, 2006). Podemos observar esse aspecto em "Compara el texto de la página anterior con el que leíste al inicio de la unidad [...]”, em que é retomado um texto trabalhado no início da unidade. 


\section{Figura 2. Análise de Clusters II}
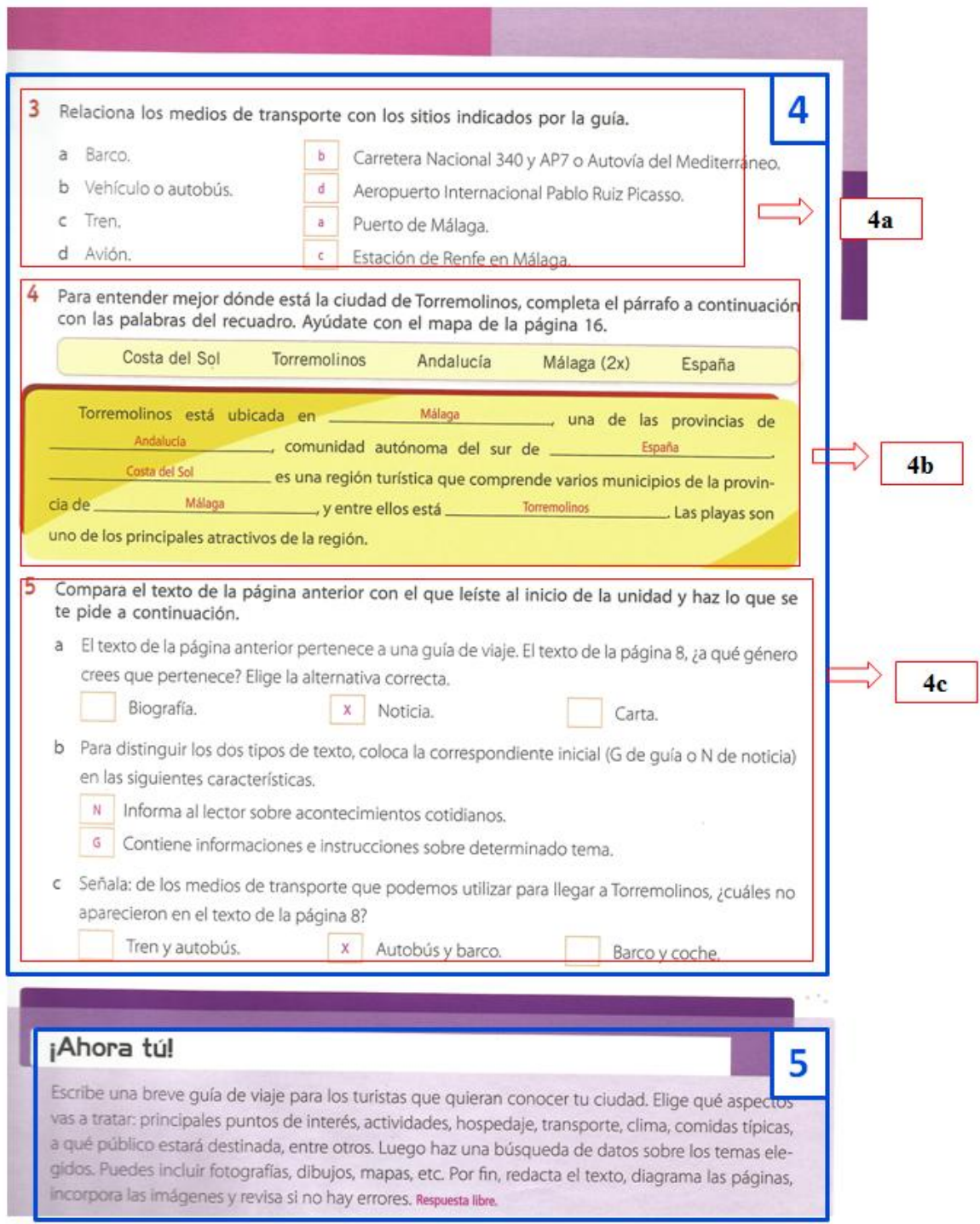

Fonte: ALMEIDA; AMENDOLA (2011, p. 17) 
No cluster 5 há uma ênfase no trabalho efetivo com os diferentes usos da linguagem escrita na sociedade, destacando-se a proposta de produção textual baseada no gênero estudado. Em ambos os clusters observa-se o predomínio da metafunção interpessoal em "Escribe una breve guia de viaje para los turístas que quieran conocer tu ciudad [...]"; "Puedes incluir fotografías, dibujos [...]", pois há estratégias de aproximação para com o leitor. A língua está constantemente em uso, com foco no processo de interação social.

\subsection{Gramática Visual}

No texto, a presença da multimodalidade é reforçada por meio das seguintes categorias apresentadas na Figura 3:

Figura 3. Análise da Gramática Visual

\section{Dado}

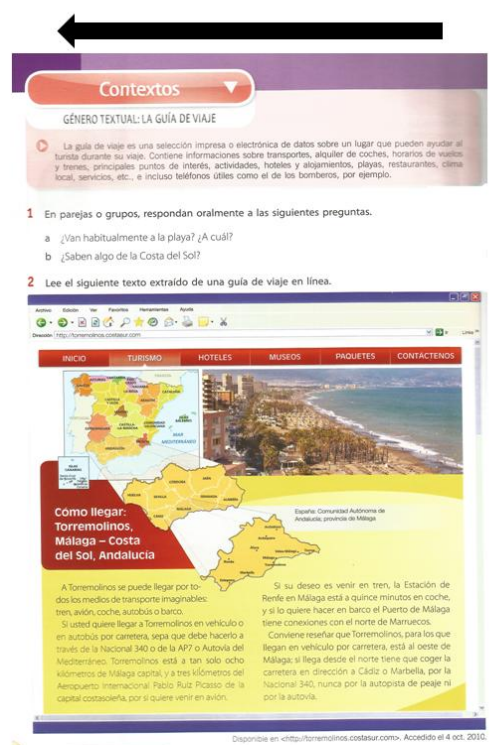

Participantes representados: cidade deTorremolinos

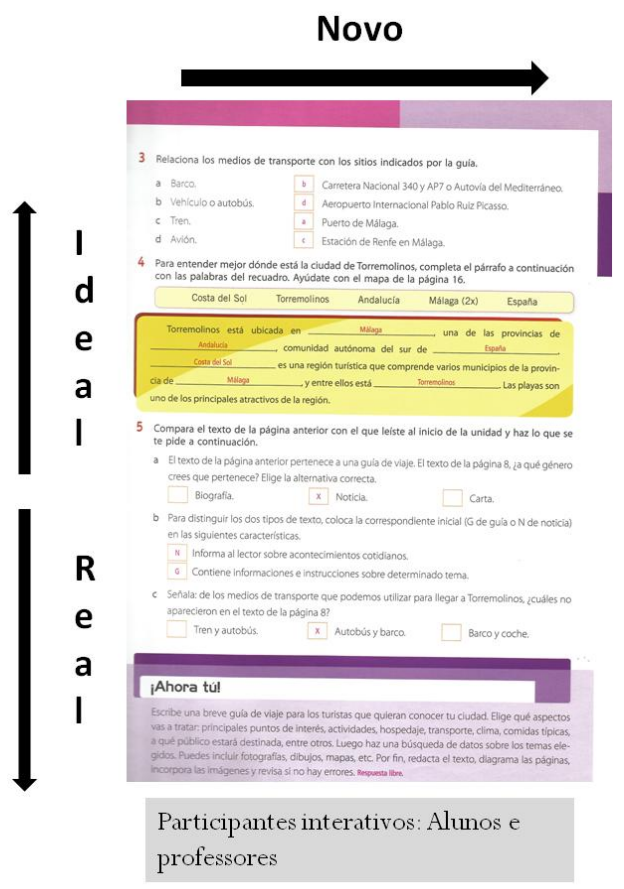

Fonte: ALMEIDA; AMENDOLA (2011, p. 16-17) 
A categoria dos participantes apresenta como participantes representados a cidade de Torremolinos, comunidade autônoma de Andaluzia, província de Málaga. Ou seja, são os participantes sobre os quais se estão produzindo imagens. Em relação aos participantes interativos, que diz respeito aos receptores para os quais se dirige a mensagem, são considerados os alunos e os professores, pois ambos são leitores do texto/viewers.

O dado e o novo é uma categoria que trabalha a disposição dos elementos à esquerda ou à direita do layout da página. Desse modo, o "dado", localizado à esquerda, refere-se ao que já é conhecido pelo leitor, ou seja, um guia eletrônico de viagem. O "novo", localizado à direita, refere-se a algo para o qual o leitor deve ter mais atenção, no caso, as atividades e como escrever um guia de viagem.

A categoria ideal e real também se refere à disposição dos elementos na página, mas em relação às margens superior e inferior. Como se observa na imagem, na página 16 , na parte superior do anúncio revela-se o "ideal", ou seja, como um guia de viagem deve ser idealmente, e na parte inferior, "o real", que se refere a um fragmento de um guia eletrônico de viagem.

No tocante à projeção e saliência, na página 16 o guia de viagem é evidenciado em primeiro plano, com as imagens do mapa mostrando a localização da cidade de Torremolinos e sua exuberante paisagem. As cores contrastantes, vermelha e amarela, remetem o leitor a um lugar quente e ensolarado. Na página 17 o foco maior é na atividade de escrita, denominada "iAhora tú!", que propõe ao aluno escrever um guia de viagem sobre sua cidade utilizando fotografias, desenhos, mapas e outras semioses.

A multimodalidade ocupa um espaço cada vez mais representativo nas práticas sociais contemporâneas, uma vez que refletem as várias mudanças decorrentes do mundo globalizado. Isso posto, a modalidade imagética atua ao lado da modalidade escrita, pois tem forte carga semântica e simbólica, o que proporciona uma leitura em conjunto com todos os outros modos semióticos do texto. Para Kress e van Leeuwen (2006), as modalidades visual e verbal são fundamentalmente distintas em suas possibilidades de representação do mundo, e mesmo diversas em relação à estrutura de composição, são complementares, visto que o visual contribui para a composição textual. 
Assim, as análises permitem reflexões sobre o texto multimodal no LD de língua espanhola, demonstrando as peculiaridades inerentes à composição semiótica que levam o aluno à leitura crítica e ultrapassam o ensino de leitura apenas de textos verbais.

Com base nas análises realizadas, podemos observar que há no texto multimodal uma interação entre o texto escrito e a imagem, mas em momento algum a modalidade não verbal é discutida nas atividades propostas como produtora de sentido no texto. As atividades utilizam o gênero discursivo guia de viagem como único fator na produção de sentidos, no entanto este deve ser considerado mais um fator entre vários produtores de sentido.

Ao texto pós-moderno acresce-se a necessidade de usar uma abordagem de leitura e de escrita que contemple todos os modos semióticos para ir além da modalidade verbal. Os recursos semióticos podem ser utilizados de diferentes formas e podem levar à construção de sentidos distintos, tendo em vista o gênero, o suporte que integram e as modalidades verbal e não verbal. Portanto, é importante que no processo de ensino/aprendizagem de línguas o professor esteja atento a esses fenômenos.

\section{Considerações finais}

O ensino de espanhol em escolas regulares de Ensino Médio e Ensino Fundamental no Brasil ainda se encontra em fase de ajustes no que tange aos envolvidos: escola, professores e alunos. É nesse contexto que se faz necessário um estudo sistematizado sobre a composição multimodal de $\mathrm{LD}$, uma vez que nele se encontram as escolhas do que se julga pertinente para o ensino de língua.

As análises permitem reflexão sobre a composição dos textos multimodais nesses LD, demonstrando as peculiaridades inerentes à composição multimodal e como a língua é entendida como parte de contexto sociocultural. $\mathrm{O}$ trabalho dos textos nesse LD, numa perspectiva multimodal, demonstra as peculiaridades tanto inerentes ao tipo de gênero como de composição semiótica, com vistas à reflexividade crítica sobre a formação de sentidos em LD de espanhol.

Portanto, a potencialidade de significação de diferentes semioses em língua estrangeira é ponto de grande importância para o 
As metafunções textual, ideacional e interpessoal em textos multimodais...

desenvolvimento de pesquisas sobre o LD no âmbito de ensino voltado à Multimodalidade.

\section{Referências}

ALMEIDA, P. A.; AMENDOLA, R. Ventana al español, v. 2. São Paulo: Moderna, 2011. p. 16-17.

BALDRY, A.; THIBAULT, P. J. Introduction: multimodal texts and genres. In: . Multimodal transcription and text analysis: a multimedia toolkit and coursebook. London: Equinox, 2006. p. 1-56.

DELL'ISOLA, R. L. P. Gêneros textuais em livros didáticos de português língua estrangeira: o que falta? In: DIAS, Reinildes; CRISTOVÃO, Vera Lúcia. (Org.). $O$ livro didático de língua estrangeira: múltiplas perspectivas. Campinas: Mercado de Letras, 2009. p. 99-120.

BAKHTIN, M. Estética da criação verbal. São Paulo: Martins Fontes, 1997.

DIONISIO, P. D.; HOFFNAGEL, J. C. (Org.). Gêneros textuais, tipificação e interação. São Paulo: Cortez, 2005.

FERRAZ, J. A. A Multimodalidade no ensino de português como segunda língua: novas perspectivas discursivas críticas. 2011. 200f. Tese (Doutorado em Linguística) - Instituto de Letras, Universidade de Brasília, Brasília, 2011.

FLICK, U. Introdução à pesquisa qualitativa. 3. ed. Trad. Joice Elias Costa. Porto Alegre: Artmed, 2009.

HALLIDAY, M. A. K. An introduction to Functional Grammar. 2. ed. London: Edward Arnold, 1994. . Language as social semiotic. London: Edward Arnold, 1978. 
JEWITT, C.; OYAMA, R. Visual meaning: a social semiotic approach. In: van LEEUWEN, T.; JEWITT, C. (Eds.). Handbook of visual analysis. London: SAGE Publications, 2007.

KOCK, I. V.; ELIAS, V. M. Ler e compreender os sentidos do texto. São Paulo: Contexto, 2006.

KRESS, G.; van LEEUWEN, T. Introduction: the grammar of visual design: the semiotic landscape: language and visual communication. In: . Reading images: the grammar of visual design. London; New York: Routledge, 2006. p. 1-42.

MAROUN, C. R. G. O texto multimodal no livro didático de português. In: VIEIRA, J. A. et al. Reflexões sobre a língua portuguesa: uma abordagem multimodal. Petrópolis: Vozes, 2007. p. 77-107.

MOURA FILHO, A. C. L. Reinventando a aula: por um contexto cooperativo para a aprendizagem de inglês como língua estrangeira. 2000. 161f. Dissertação (Mestrado em Linguística) - Instituto de Letras, Universidade de Brasília, Brasília, 2000.

SEDYCIAS, J. Por que os brasileiros devem aprender espanhol? In: SEDYCIAS, J. (Org.). O ensino do espanhol no Brasil: passado, presente e futuro. São Paulo: Parábola Editorial, 2005. p. 35-44.

VIEIRA, J. A. Novas perspectivas para o texto: uma visão multissemiótica. In: VIEIRA, J. A. et al. Reflexões sobre a língua portuguesa: uma abordagem multimodal. Petrópolis: Vozes, 2007. p. 9-33.

Recebido em: 21/08/2017

Aceito em: 26/12/2017

Title: Textual, ideational and interpersonal metafunctions in multimodal Spanish coursebooks 